\title{
Yi Qi Qing Re Gao-containing serum inhibits lipopolysaccharide-induced rat mesangial cell proliferation by suppressing the Wnt pathway and TGF- $\beta 1$ expression
}

\author{
LIPING YANG $^{1 *}$, XUEYAN SUN ${ }^{2 *}$, YONGLI ZHAN ${ }^{1}$, HUIJIE LIU $^{2}$, YUMIN WEN $^{2}$, \\ HUIMIN MAO ${ }^{2}$, XI DONG ${ }^{3}$ and PING $\mathrm{LI}^{3}$
}

\begin{abstract}
${ }^{1}$ Department of Nephrology, Guang'Anmen Hospital of China Academy of Traditional Chinese Medicine Sciences, Beijing 100053; ${ }^{2}$ Beijing University of Chinese Medicine, Chaoyang, Liaoning 100029; ${ }^{3}$ Department of Pharmacology, Institute of Clinical Medical Sciences, China-Japan Friendship Hospital, Beijing 100029, P.R. China
\end{abstract}

Received June 14, 2014; Accepted July 13, 2015

DOI: $10.3892 /$ etm.2016.3027

\begin{abstract}
The aim of the present study was to investigate the effect of Yi Qi Qing Re Gao-containing serum (YQ-S) on rat mesangial cell (MC) proliferation and to investigate the underlying mechanism. MCs were divided into the control, lipopolysaccharide (LPS)-stimulated, YQ-S and fosinopril-containing serum (For-S) groups, and cultured for $48 \mathrm{~h}$. An MTT assay was used to evaluate the proliferation of MCs. In addition, reverse transcription-quantitative polymerase chain reaction and western blot analysis were conducted to detect the expression levels of Wnt $4, \beta$-catenin and transforming growth factor (TGF)- $\beta 1$ in MCs. The results indicated that YQ-S inhibited LPS-induced MC proliferation. The Wnt 4 and TGF- $\beta 1 \mathrm{mRNA}$ expression levels were reduced in the YQ-S group $(\mathrm{P}<0.01$ or $\mathrm{P}<0.05)$. Furthermore, the Wnt $4, \beta$-catenin and TGF- $\beta 1$ protein expression levels were suppressed in the $\mathrm{YQ}-\mathrm{S}$ group $(\mathrm{P}<0.01$ or $\mathrm{P}<0.05)$. Therefore, YQ-S appears to inhibit MC proliferation, and its mechanism may involve the inhibition of the Wnt signaling pathway and downregulation of TGF- $\beta 1$ expression.
\end{abstract}

\section{Introduction}

Chronic kidney disease (CKD) is a major challenge for global public health care, due to its irreversible progression, low awareness and high cost (1). Due to the progressive aging of

Correspondence to: Dr Ping Li, Department of Pharmacology, Institute of Clinical Medical Sciences, China-Japan Friendship Hospital, 2 Yinghua Dongjie, Beijing 100029, P.R. China

E-mail: pingli1234@yeah.net

*Contributed equally

Key words: Yi Qi Qing Re Gao, mesangial cell proliferation, lipopolysaccharide, Wnt signaling pathway, transforming growth factor- $\beta 1$ the general population, and the emerging epidemic of obesity and diabetes, CKD is now one of the three leading causes of mortality worldwide $(1,2)$. Studies regarding the pathogenesis of CKD have predominantly focused on glomerular sclerosis and interstitial fibrosis, with disturbance of extracellular matrix (ECM) homeostasis (i.e. synthesis and degradation) a common factor (3). Mesangial lesions, caused by mesangial cell (MC) proliferation and accumulation of ECM, are universal morphological manifestations of renal diseases that involve the mesangium. There are numerous growth factors, cytokines and signaling pathways that are involved in the process of mesangial fibrosis, among which transforming growth factor- $\beta 1$ (TGF- $\beta 1$ ) is the most versatile, with functions in cell growth, apoptosis, proliferation, and ECM production (4). TGF- $\beta 1$ is able to affect MC proliferation, and stimulate the synthesis and inhibit the degradation of ECM in an autocrine or paracrine manner, leading to relentless progression of glomerular sclerosis (5).

The Wnt signaling pathway is a key regulator of embryonic development, tissue homeostasis, cell apoptosis, proliferation and differentiation (6-8). There are 19 known Wnts, which mediate at least three divergent signaling pathways: The $\beta$-catenin dependent pathway (canonical Wnt pathway), the $\mathrm{Ca}^{2+}$-pathway, and the planar cell polarity-pathway; the latter two pathways are also known as non-canonical Wnt pathways. In the canonical Wnt pathway, Wnt proteins bind to a receptor complex formed by Frizzled and low-density lipoprotein receptor-related protein 5 or 6 , which leads to disassembly of the $\beta$-catenin destruction complex, which is composed of axin, adenomatous polyposis coli protein, and glycogen synthase kinase- $3 \beta$ (8). Disassembly of the $\beta$-catenin destruction complex hinders the normal phosphorylation and ubiquitination process of cytoplasmic $\beta$-catenin, allowing it to accumulate in the cytosol and translocate into the nucleus, where it stimulates the transcription of its target genes, including Twist, Snail, fibronectin, and matrix metalloproteinase-7 (9). The Wnt pathway has previously been demonstrated to be involved in renal tubular atrophy and interstitial fibrosis of an obstructed renal model $(10,11)$, podocyte apoptosis and dysfunction, albuminuria and slit diaphragm 
abnormalities (12-14), and high glucose-induced MC apoptosis $(15,16)$. Interactions between $\mathrm{Wnt} / \beta$-catenin and TGF- $\beta$ signaling pathways have been shown to be important in the pathogenesis of fibrosis $(17,18)$. In addition, manipulation of the Wnt pathway may rescue TGF- $\beta 1$ mediated fibrosis.

Yi Qi Qing Re Gao (YQ) is a traditional Chinese medicine mixture developed by Zhan and Dai (19), which has been used for decades with satisfactory clinical effects. In a previous clinical study, YQ was demonstrated to reduce proteinuria, elevate serum albumin, decrease serum cholesterol, and ameliorate certain symptoms associated with chronic nephritis (19). Furthermore, a previous animal study in an adriamycin rat model suggested that YQ may be able to reduce glomerular mesangial collagen type IV, fibronectin and laminin content (20). Our recent study revealed that YQ was able to attenuate podocyte injury and inhibit vascular endothelial grow th factor overexpression in a puromycin aminonucleoside rat model (21). However, the mechanisms underlying the effects of YQ on MC proliferation and glomerular sclerosis remain to be elucidated. The present study aimed to investigate the expression of Wnt pathway-associated molecules and TGF- $\beta 1$ in LPS-stimulated MCs, and to determine the effects of YQ on this pathway, in order to provide evidence for the role of YQ in the prevention and treatment of glomerulosclerosis.

\section{Materials and methods}

Animals. A total of 40 healthy male Wistar rats (age, 7-8 weeks), weighing $250 \pm 20 \mathrm{~g}$, were purchased from Beijing China Fukang Biological Technology Co., Ltd. (no. SCXK 2009-0007; Beijing, China). Rats were housed in the specific pathogen-free animal facility at the China-Japan Friendship Hospital (Beijing, China), with free access to water and standard rat chow. This study was approved by the Ethics Committee of the China-Japan Friendship Hospital and conducted in accordance with the Guiding Principles for the Care and Use of Laboratory Animals (no. 2010-A10).

Cell line. A rat mesangial cell line was purchased from Peking Union Medical College (no. HBZY-1; Beijing, China).

Reagents and instruments. Minimum essential medium (MEM), streptomycin and ampicillin, phosphate-buffered saline (PBS) and trypsin were all purchased from GE Healthcare (Logan, UT, USA). In addition, fetal bovine serum (FBS) was obtained from Gibco Life Technologies (Carlsbad, CA, USA); lipopolysaccharide (LPS) was purchased from Sigma-Aldrich (St. Louis, MO, USA); MTT [3-(4,5-dimethylthiazol-2-yl)-2,5-diphenyl tetrazolium bromide] was from Enzo Life Sciences, Inc. (Farmingdale, NY, USA); TRIzol reagent was from Invitrogen Life Technologies (Carlsbad, CA, USA); RevertAid ${ }^{\mathrm{TM}}$ First Strand cDNA Synthesis kit was from Fermentas, Thermo Fisher Scientific (Vilnius, Lithuania); Wnt4 goat polyclonal antibody (cat. no. sc-5214) was from Santa Cruz Biotechnology, Inc. (Dallas, TX, USA); mouse TGF- $\beta 1$ monoclonal antibody (cat. no. ab64715) was from Abcam (Cambridge, UK); rabbit $\beta$-catenin monoclonal antibody (cat. no. 8480S) was from Cell Signaling Technology, Inc. (Danvers, MA, USA); goat anti-mouse IgG and goat anti-rabbit IgG antibodies were from Beijing Zhongshanjinqiao
Biotechnology Co., Ltd (Beijing, China). The instruments used in the present study were as follows: ABI 2720 thermal cycler (Applied Biosystems Life Technologies, Foster City, CA, USA); AlphaImager TM2200 gel imaging system (Alpha Innotech Corporation, San Leandro, CA, USA); 1 X51 inverted microscope (Olympus Corporation, Tokyo, Japan); and NAPCO $\mathrm{CO}_{2}$ incubator (Thermo Fisher Scientific, Inc., San Jose, CA, USA).

Experimental drugs. YQ was obtained from Guang'Anmen Hospital (Beijing, China; certificate no. 98; Beijing Health \& Drug no. 058). The mixture included: 72 g Radix Astragali Mongolici (Huang Qi), 54 g Rhizoma Atractylodis Macrocephalae (Bai Zhu), 36 g Radix Ledebouriellae (Fang Feng), 72 g Flos Lonicerae (Jin Yin Hua), 72 g Fructus Forsythiae Suspensae (Lian Qiao), 54 g Herba Duchesneae Indicae (She Mei), 180 g Herba Hedyotis Diffusae (Bai Hua She She Cao), 72 g Poria Cocos (Fu Ling), 125 g Rhizoma Alismatis (Ze Xie), 180 g Herba Leonuri (Yi Mu Cao), 180 g Rhizoma Imperatae (Bai Mao Gen) and $70 \mathrm{~g}$ Rhizoma Dioscoreae Nippponicae (Chuan Shan Long). Herbal medicines were prepared as follows: Water decoction for $30 \mathrm{~min}$, followed by concentration of the supernatant under ordinary pressure, centrifugation at 2,000 x g for $15 \mathrm{~min}$, and sterilization by filtration. The final standardized product consisted of $4.5 \mathrm{~g}$ crude medicine per milliliter. fosinopril tablets, containing fosinopril sodium, were provided by Sino-American Shanghai Squibb Pharmaceutical Ltd. (Shanghai, China).

Preparation of drug-containing sera. After three days of acclimation, $40 \mathrm{Wistar}$ rats were divided at random into three groups, including the YQ $(n=10)$, fosinopril $(n=10)$ and normal $(n=20)$ groups. Rats received an intragastric dose of YQ $(5.7 \mathrm{~g} / \mathrm{kg}$, which corresponds to 20 times the adult clinical dose), fosinopril $(1.67 \mathrm{mg} / \mathrm{kg}$, which corresponds to 10 times the adult clinical dose), or an equal volume of distilled water, twice a day for seven days. Abdominal aortic blood (5-10 ml) was collected following the final drug administration. Blood samples were allowed to stand at $4^{\circ} \mathrm{C}$ for $4 \mathrm{~h}$, followed by centrifugation at $900 \mathrm{x}$ g for $10 \mathrm{~min}$ at $4^{\circ} \mathrm{C}$. Sera were carefully extracted by suction and then incubated in a $56^{\circ} \mathrm{C}$ water bath for $30 \mathrm{~min}$ to inactivate complements and antibodies present in the sera. Subsequent to $0.22 \mu \mathrm{m}$ filter-sterilization, the sera were stored in sterile centrifuge tubes at $-20^{\circ} \mathrm{C}$.

Recovery and passage of cells. Frozen rat MCs (HBZY-1) were removed from liquid nitrogen, and rapidly transferred to a $37^{\circ} \mathrm{C}$ water bath for $\sim 1$ min until dissolved into a mixture of ice and water. MCs were subsequently transferred to a $25 \mathrm{~cm}^{2}$ culture flask with $5 \mathrm{ml}$ MEM containing 10\% FBS, and $100 \mathrm{IU} / \mathrm{ml}$ streptomycin and ampicillin, and then placed in a $5 \% \mathrm{CO}_{2}$ incubator at $37^{\circ} \mathrm{C}$. Following overnight culture until the cells became adherent, the medium was changed. The medium was discarded when the MCs were in the logarithmic phase, and the cells were washed twice with PBS, followed by the addition of $1 \mathrm{ml}$ trypsin $(0.25 \%)$. When the cells exhibited a round shape, culture medium was immediately added to terminate the digestion. Subsequently, the cell suspension was transferred to a new culture flask containing $10 \%$ FBS-containing MEM, and placed in an incubator with $5 \% \mathrm{CO}_{2}$ at $37^{\circ} \mathrm{C}$ for $3-5$ days 
Table I. Polymerase chain reaction primers and reaction parameters.

\begin{tabular}{|c|c|c|c|c|}
\hline Primer & Primer sequence & $\begin{array}{l}\text { Fragment } \\
\text { length (bp) }\end{array}$ & $\begin{array}{c}\text { Annealing } \\
\text { temperature }\left({ }^{\circ} \mathrm{C}\right)\end{array}$ & Cycles \\
\hline Wnt4 & $\begin{array}{l}\text { F 5'-CGGGAAGGTGGTGACACAAG-3' } \\
\text { R 5'-GCTCGCCAGCATGTCTTTAC-3' }\end{array}$ & 375 & 58 & 34 \\
\hline$\beta$-catenin & $\begin{array}{l}\text { F 5'-AATGGCTTGGAATGAGACTG-3' } \\
\text { R 5'-AGCCCATCAACTGGATAGTC-3' }\end{array}$ & 198 & 56 & 30 \\
\hline TGF- $\beta 1$ & $\begin{array}{l}\text { F 5'-TACCATGCCAACTTCTGTCTG-3' } \\
\text { R 5'-CACGATCATGTTGGACAACTG-3' }\end{array}$ & 204 & 58 & 29 \\
\hline Cyclophilin B & $\begin{array}{l}\text { F 5'-GTGGTTTTCGGCAAAGTTCTG-3' } \\
\text { R 5'-GGCAAAGGGTTTCTCCACTTC-3' }\end{array}$ & 147 & 56 & 29 \\
\hline
\end{tabular}

TGF- $\beta 1$, transforming growth factor- $\beta 1$; F, forward; R, reverse.

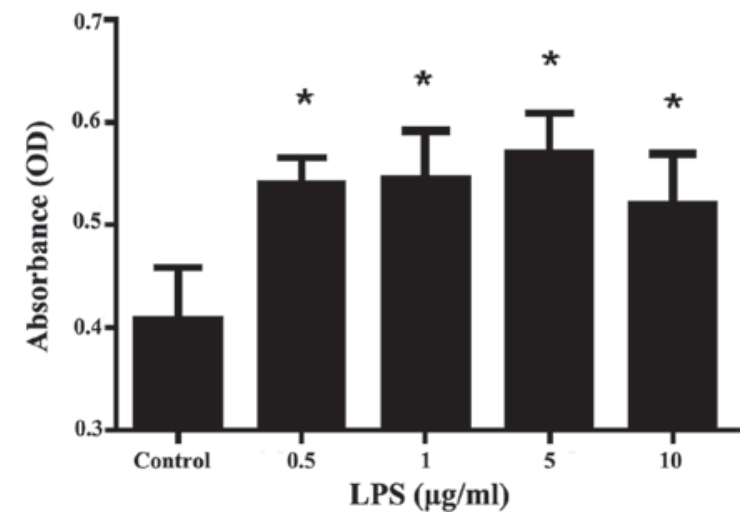

Figure 1. Different concentrations of LPS on mesangial cell proliferation $(n=3) .{ }^{*} \mathrm{P}<0.01$ vs. control group. OD, optical density; LPS, lipopolysaccharide.

until they reached $80-100 \%$ confluence. The 5 th generation of MCs was used for subsequent experimentation.

Experimental design. Cells of the 5th generation were transferred into 96 -well plates $\left(3 \times 10^{3} /\right.$ well), and incubated with MEM supplemented with 5\% FBS and 20\% normal rat serum for $24 \mathrm{~h}$. Subsequently, the cells were incubated with MEM containing $2 \%$ FBS for $24 \mathrm{~h}$, in order to be synchronized at $\mathrm{G}_{0}$ phase. The cells were divided into: Control group (incubated with $\mathrm{MEM}+5 \% \mathrm{FBS}+20 \%$ normal rat serum), the LPS-stimulated (LPS) group (incubated with MEM $+5 \%$ $\mathrm{FBS}+20 \%$ normal rat serum $+5 \mu \mathrm{g} / \mathrm{ml} \mathrm{LPS})$, the YQ containing serum (YQ-S) group (incubated with MEM $+5 \%$ FBS $+20 \%$ YQ-S $+5 \mu \mathrm{g} / \mathrm{ml}$ LPS $)$, the fosinopril containing serum (For-S) group (incubated with MEM + 5\% FBS + 20\% For-S $+5 \mu \mathrm{g} / \mathrm{ml}$ LPS ). There were 6 wells for each group.

Effect of LPS and drug-containing serum on rat MC proliferation. Once the cells were synchronized at $\mathrm{G}_{0}$ phase after $24 \mathrm{~h}$, the supernatant was removed and $200 \mu \mathrm{l}$ medium supplemented with 5\% FBS and various concentrations of LPS $(0.0,0.5,1.0,5.0$ and $10.0 \mu \mathrm{g} / \mathrm{ml})$, and YQ-S or For-S $(5,10$ and $20 \%$ ) were added to each well ( $n=3$, triplicate wells). The cells were further incubated for $48 \mathrm{~h}$, and subsequently $150 \mu \mathrm{l}$ MTT $(5 \mathrm{mg} / \mathrm{ml})$ was added to each well. Following incubation at $37^{\circ} \mathrm{C}$ for $4 \mathrm{~h}$, the supernatant was discarded carefully, and $150 \mu \mathrm{l}$ DMSO was added to each well. Following shaking at room temperature for $10 \mathrm{~min}$, the optical density values were measured at $492 \mathrm{~nm}$ using a microplate absorbance reader (Model 680; Bio-Rad Laboratories, Inc., Hercules, CA, USA). Each experiment was repeated three times.

Reverse transcription-quantitative polymerase chain reaction (RT-qPCR) for the detection of Wnt4, $\beta$-catenin and TGF- $\beta 1$ $m R N A$ expression levels. MCs in the logarithmic growth phase were digested and suspended, and $1 \times 10^{5}$ cells were seeded in a $100 \mathrm{~mm}$ culture dish and incubated for $24 \mathrm{~h}$ in order to reach adherence. After $48 \mathrm{~h}$ of stimulation according to the various groups, the cells were lysed with TRIzol to extract the total RNA, which was then reverse transcribed into cDNA. PCR amplification primers were synthesized by Beijing Qing Ke New Industrial Biotechnology Co., Ltd. (Beijing, China). Primer sequences and reaction conditions are presented in Table I. PCR was performed in triplicate in a final volume of 12.5 $\mu \mathrm{l}$ : 6.25 $\mu \mathrm{l}$ PCR mix (Beijing ComWin Biotech Co., Ltd., Beijing, China), $2 \mu$ l diluted cDNA products, $1 \mu \mathrm{l}$ of each paired primer, and $3.25 \mu \mathrm{l}$ deionized water. PCR was carried out using an ABI 2720 thermal cycler (Applied Biosystems Life Technologies). Cycling conditions were as follows: Initial denaturation for $2 \mathrm{~min}$ at $94^{\circ} \mathrm{C}$, followed by 29 cycles (for cyclophilin B and TGF- $\beta 1$ ), 30 cycles (for $\beta$-catenin) or 34 cycles (for Wnt4) of denaturation for $30 \mathrm{sec}$ at $94^{\circ} \mathrm{C}$, extension for $1 \mathrm{~min}$ at $72^{\circ} \mathrm{C}$, and a final elongation for $10 \mathrm{~min}$ at $72^{\circ} \mathrm{C}$. PCR products were loaded onto a $1.2 \%$ agarose gel and electrophoresis was performed at $100 \mathrm{~V}$ constant voltage for $30 \mathrm{~min}$. Gel images were analyzed using ImageJ $1.40 \mathrm{~g}$ software (National Institutes of Health, Bethesda, MD, USA), which was used to determine each gray value of the target band. Relative quantities of each target gene were represented as the ratio of the gray values of target to that of cyclophilin B.

Western blot analysis of Wnt4, $\beta$-catenin and TGF- $\beta 1$ protein expression levels. Following $48 \mathrm{~h}$ of stimulation according to the grouping aforementioned, the MCs were collected and lysed with cell lysis buffer $(150 \mathrm{mM} \mathrm{NaCl}$, $1 \mathrm{mM}$ EDTA, $20 \mathrm{mM}$ Tris $\mathrm{HCl}, \mathrm{pH}$ 7.4) and $1 \mathrm{X}$ protein 

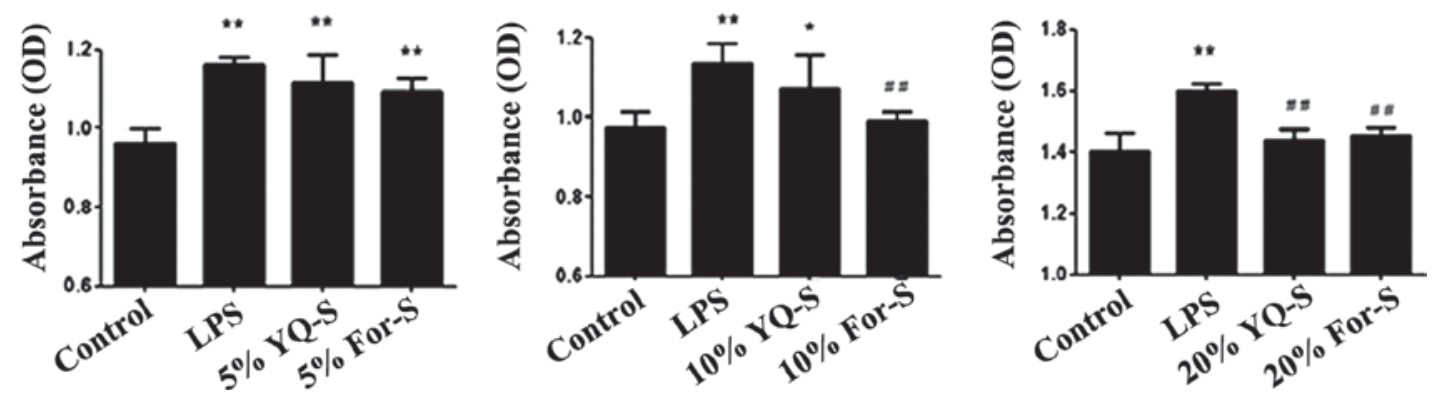

Figure 2. Different concentrations containing serum on proliferation of mesangial cells. ${ }^{*} \mathrm{P}<0.05$ and ${ }^{* *} \mathrm{P}<0.01$ vs. control group; ${ }^{\# \#} \mathrm{P}<0.01$ vs. LPS stimulation group. OD, optical density; LPS, lipopolysaccharide; YQ-S, Yi Qi Qing Re Gao-containing serum; For-S, fosinopril-containing serum.
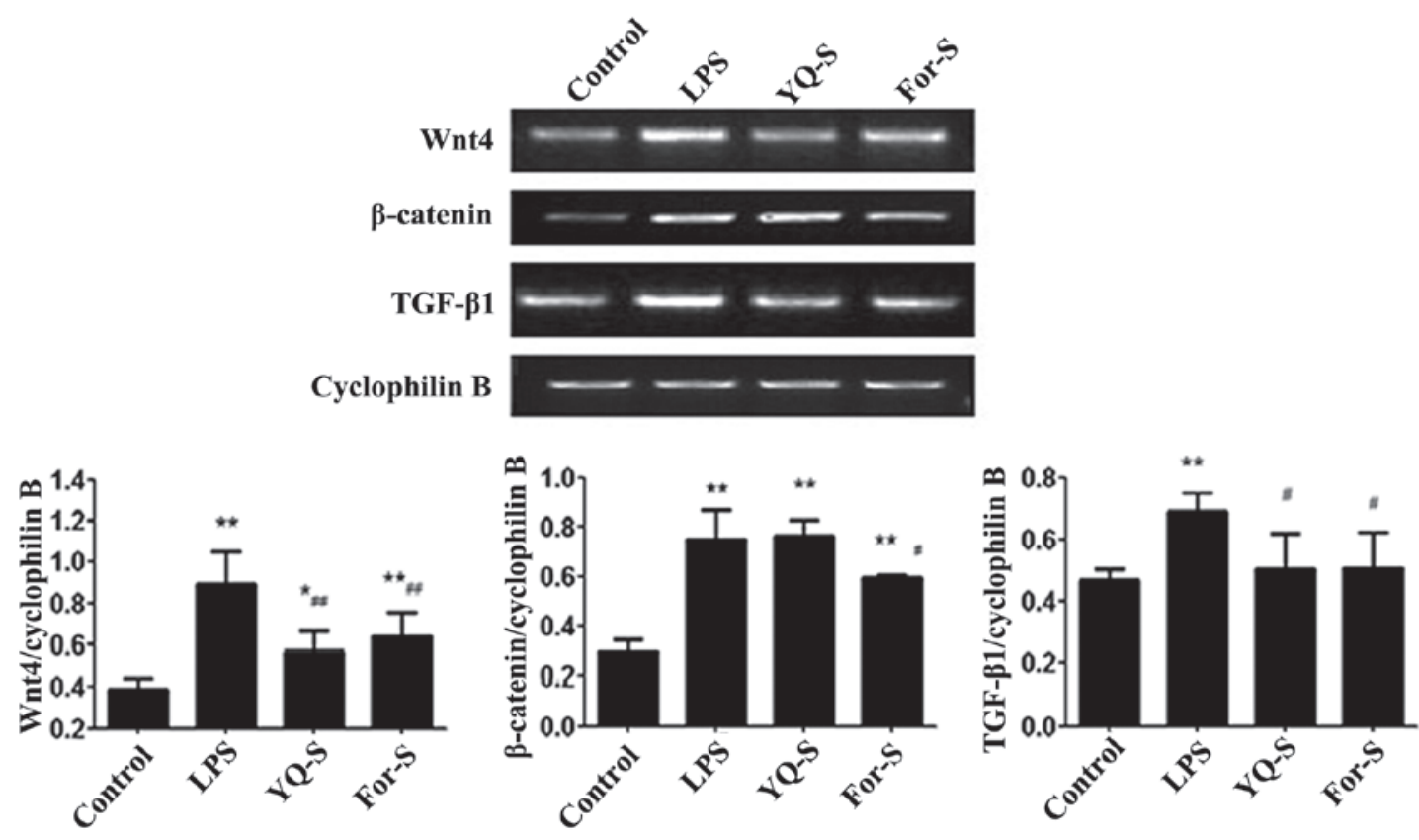

Figure 3. Wnt4, $\beta$-catenin and TGF- $\beta 1$ mRNA expression in rat mesangial cells. ${ }^{*} \mathrm{P}<0.05$ and ${ }^{* *} \mathrm{P}<0.01$ vs. control group; ${ }^{\#} \mathrm{P}<0.05$ and ${ }^{\# \#} \mathrm{P}<0.01$ vs. LPS stimulation group. LPS, lipopolysaccharide; YQ-S, Yi Qi Qing Re Gao-containing serum; For-S, fosinopril-containing serum; TGF- $\beta 1$, transforming growth factor- $\beta 1$.

inhibitor cocktail for extraction of total proteins. The protein concentrations of the samples were determined by Bradford assay (Beijing Solarbio Science \& Technology Co., Ltd., Beijing, China). Samples containing $60 \mu \mathrm{g}$ proteins were loaded onto $10 \%$ SDS-PAGE gel and separated by electrophoresis. The initial electrophoresis with condensed gel was conducted at $80 \mathrm{~V}$ for $25 \mathrm{~min}$, followed by electrophoresis with separation gel at $150 \mathrm{~V}$ for $50 \mathrm{~min}$. The proteins were then electrotransferrd to a polyvinylidene fluoride membrane (EMD Millipore, Billerica, MA, USA), and the membranes were blocked with 5\% skim milk in Tris-buffered saline containing $0.1 \%$ Tween 20 (TBST) for $2 \mathrm{~h}$. The membrane was then incubated at $4^{\circ} \mathrm{C}$ overnight with the primary antibodies against Wnt4 $(1: 1,000), \beta$-catenin $(1: 1,000)$ and TGF- $\beta 1$ (1:2,000), and was subsequently washed three times with TBST for $10 \mathrm{~min}$. Horseradish peroxidase-conjugated second antibodies $(1: 3,000)$ were then added. Following $1 \mathrm{~h}$ incubation with agitation, the membranes were washed three times with TBST for $10 \mathrm{~min}$. Following visualization in the dark for $5 \mathrm{~min}$ in a Tanon 4500 chemical imaging system, the images were analyzed using ImageJ $1.40 \mathrm{~g}$ soft- ware. Relative expression levels of the target proteins were quantified as the ratio of the target bands to that of $\beta$-actin.

Statistical analysis. Experimental data were analyzed using SPSS statistical software, version 17.0 (SPSS, Inc., Chicago, IL, USA). Measurement data are expressed as the mean \pm standard deviation. Measurement data among different groups were compared using single-factor analysis of variance. Groups were compared using the least significant difference test and $\mathrm{P}<0.05$ was considered to indicate a statistically significant difference.

\section{Results}

Effect of LPS on rat MC proliferation. Compared with the control group, different concentrations of LPS $(0.5,1.0,5.0$ and $10 \mu \mathrm{g} / \mathrm{ml})$ were able to stimulate rat MC proliferation to various degrees $(\mathrm{P}<0.01)$, among which the effect of $5.0 \mu \mathrm{g} / \mathrm{ml}$ LPS was the most evident. Combined with the results of our previous study (22), LPS $5.0 \mu \mathrm{g} / \mathrm{ml}$ was selected as the stimulation dose for the subsequent experiments (Fig. 1). 


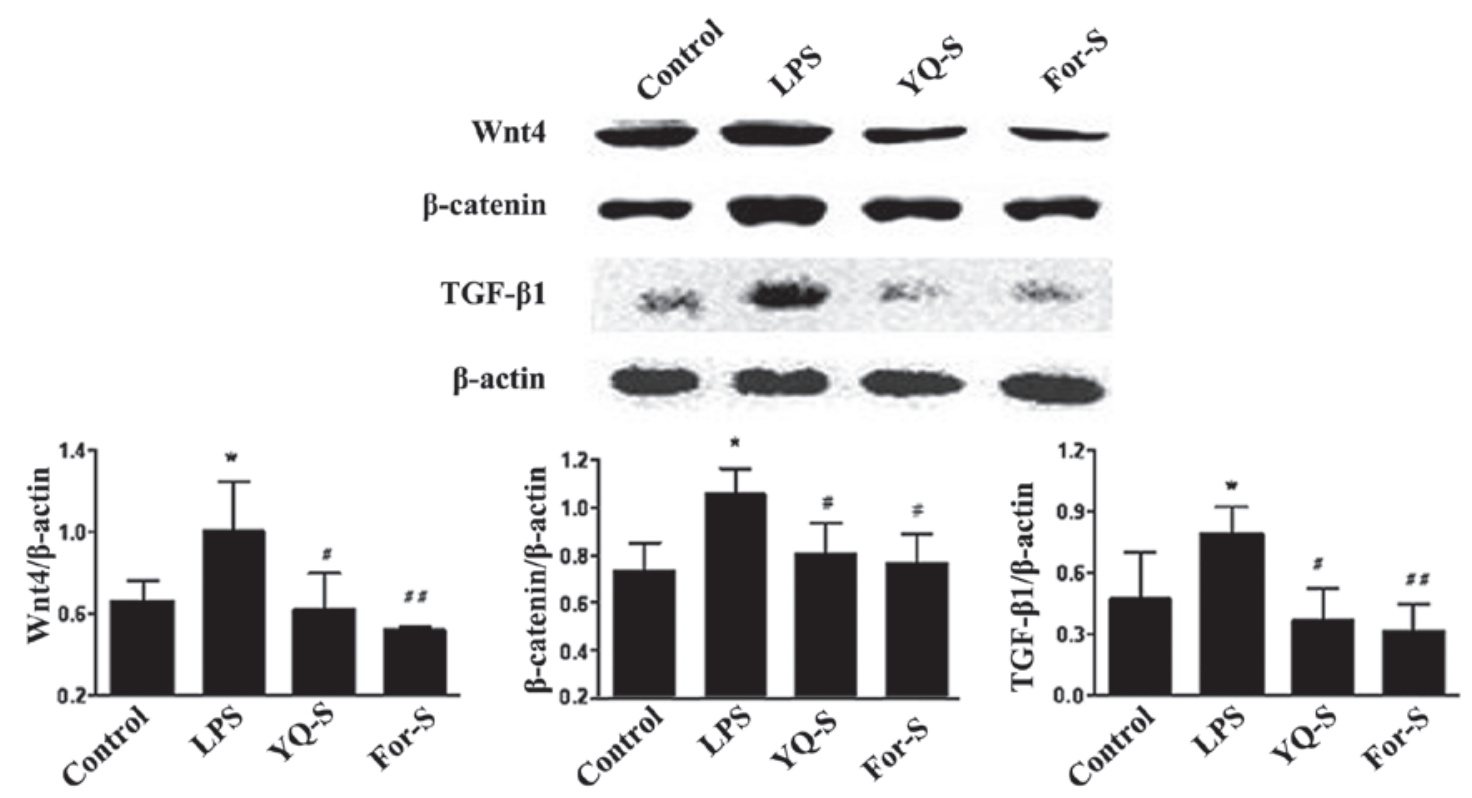

Figure 4. Wnt4, $\beta$-catenin and TGF- $\beta 1$ protein expression levels in rat mesangial cells. ${ }^{*} \mathrm{P}<0.05$ vs. control group; ${ }^{\#} \mathrm{P}<0.05$ and ${ }^{\# \#} \mathrm{P}<0.01$ vs. LPS stimulation group. LPS, lipopolysaccharide; YQ-S, Yi Qi Qing Re Gao-containing serum; For-S, fosinopril-containing serum; TGF- $\beta 1$, transforming growth factor- $\beta 1$.

Effect of $Y Q-S$ on rat MC proliferation. The MTT assay results indicated that, compared with the LPS group, 5\% YQ-S and $5 \%$ For-S exerted no significant inhibition on MC proliferation. Following treatment of the MCs with $10 \%$ For-S or $10 \%$ YQ-S, only For-S exerted a significant inhibitory effect on LPS-induced MC proliferation $(\mathrm{P}<0.01)$. In the MCs that received a $20 \%$ serum containing intervention, both YQ-S and For-S significantly inhibited MC proliferation $(\mathrm{P}<0.01)$. Therefore, $20 \%$ serum was selected as the appropriate dose for the subsequent intervention experiments (Fig. 2).

Effect of YQ-S on LPS-stimulated Wnt4, $\beta$-catenin and $T G F-\beta 1$ expression. After LPS stimulation for $48 \mathrm{~h}$, the MCs were collected for RT-qPCR and western blot analysis. The results indicated that, compared with control group, the expression levels of Wnt4, $\beta$-catenin and TGF- $\beta 1$ were significantly increased $(\mathrm{P}<0.01$ or $\mathrm{P}<0.05)$. Following stimulation of the MCs with the drug-containing serum for $48 \mathrm{~h}$, RT-qPCR results indicated that, compared with LPS group, the Wnt 4 and TGF- $\beta 1$ mRNA expression levels were significantly reduced in the YQ-S and For-S groups $(\mathrm{P}<0.01$ or $\mathrm{P}<0.05)$, while $\beta$-catenin mRNA expression was significantly reduced in the For-S group $(\mathrm{P}<0.05)$. Western blot analysis revealed that, compared with the LPS stimulation group, Wnt $4, \beta$-catenin and TGF- $\beta 1$ protein expression levels were significantly reduced in the YQ-S and For-S groups $(\mathrm{P}<0.01$ or $\mathrm{P}<0.05$; Figs. 3 and 4 ).

\section{Discussion}

MCs are located in the central stalk of glomeruli and have various fundamental roles, including maintaining the structural backbone of the glomerular tuft, regulating capillary blood flow and thus glomerular filtration rate, generation of the mesangial matrix, and manipulation of immune complexes (5). Injuries to MCs, predominantly cell proliferation, hypertrophy, apoptosis, and ECM deposition, are pathological hallmarks of a wide spectrum of glomerular diseases, which lead directly to progressive renal failure (23). The mechanisms associated with MC injury have recently garnered extensive attention. The Wnt signaling pathway is an evolutionarily conserved pathway across species, which is closely associated with numerous kidney diseases, including ischemic renal injury, acute kidney injury (AKI), diabetic nephropathy, renal interstitial fibrosis and renal tumors. In ischemia-reperfusion injury of AKI, $\beta$-catenin ameliorates tubular epithelial cell apoptosis via activation of the Akt pathway, induction of survival and suppression of p53 (24). Activation of the canonical Wnt pathway contributes to obstructive renal injury, and the Wnt antagonist Dickkopf-1 (DKK-1) protects against renal fibrosis by inhibiting Wnts (10). In podocyte injury and proteinuric kidney diseases, the Wnt pathways are essential regulators and potential therapeutic targets $(13,14)$. Studies regarding the role of the Wnt signaling pathway in MCs have mainly focused on hyperglycemic conditions $(15,16,25,26)$. Lin et al $(15)$ observed that in diabetic nephropathy, the Wnt/ $\beta$-catenin signaling pathway serves a crucial role in the regulation of MC proliferation. In vitro, high glucose-induced apoptosis of MCs is accompanied by reduced expression of Wnt4 and Wnt5a. In addition, transfection of MCs with Wnt4, Wnt5a or persistent activation of $\beta$-catenin, was able to inhibit high glucose-induced mesangial apoptosis. Furthermore, treatment with simvastatin restored $\mathrm{Wnt} 4, \mathrm{Wnt} 5 \mathrm{a}$ and $\beta$-catenin expression in MCs and attenuated diabetic kidney injuries both in vivo and in vitro (16). In addition, it has been demonstrated that abrogation of oxidative stress may restore $\mathrm{Wnt} 5 \mathrm{a} / \beta$-catenin signaling and attenuate high glucose-induced MC apoptosis (25). DKK-1 expression was also increased in these same conditions, and mediated c-Jun, TGF- $\beta 1$, and fibronectin expression, whereas stable $\beta$-catenin expression alleviated DKK-1-induced profibrotic factors, indicating that $\beta$-catenin 
may be a potential therapeutic target of MC dysfunction of diabetic nephropathy (26). In immune-mediated MC injury, the Wnt pathway has been demonstrated to be involved in the anti-Thy-1.1 rat model of glomerulonephritis (27), and development of lupus nephritis (28). However, there is currently scarce in vitro evidence regarding Wnts and $\beta$-catenin expression in LPS-stimulated MCs. As demonstrated in the present study, following stimulation of MCs with LPS for $48 \mathrm{~h}$, the expression levels of $\mathrm{Wnt} 4$ and $\beta$-catenin were significantly elevated, indicating that both the canonical and non-canonical Wnt pathways were activated, and treatment with YQ-S was able to attenuate MC proliferation by inhibiting the Wnt signaling pathways. Further studies are required to explore the mechanisms underlying this phenomenon. Previous studies have indicated that TGF- $\beta 1$ is a key mediator of glomerular sclerosis and MC injury $(4,29,30)$. Crosstalk between TGF- $\beta 1$ and the canonical Wnt signaling pathway has recently garnered much attention. In cultured MCs, high glucose levels increased TGF- $\beta 1$ and fibronectin expression, and reduced Wnt4, Wnt5a and $\beta$-catenin expression. Restoring Wnt4, Wnt5a and cytosolic $\beta$-catenin significantly abrogated TGF- $\beta 1$ expression, and exogenous inhibitors of the Wnt pathway also significantly alleviated TGF- $\beta 1$-induced renal fibrosis, thus indicating that the Wnt pathway, particularly the $\beta$-catenin-associated pathway, is an important regulator of TGF- $\beta 1$ expression in MCs (18). Furthermore, it has been demonstrated that, in experimental fibrosis, TGF- $\beta 1$ may decrease DKK-1 levels in a p38-dependent manner, thus stimulating the canonical Wnt pathway (17). Wnt11 was identified by a gene screen study as the direct target of the stimulated TGF- $\beta 1 / \mathrm{Smad} 3$ pathway in renal epithelial cells, and further transferred its signals by the c-Jun N-terminal kinase (JNK) pathway (31). Zu et al previously demonstrated that LPS induced MC proliferation and upregulated TGF- $\beta 1, \mathrm{c}-\mathrm{jun}$, and c-fos (22). The present study demonstrated that TGF- $\beta 1$ expression was elevated after $48 \mathrm{~h}$ incubation with LPS, as was Wnt4 and $\beta$-catenin, thus indicating that the $\mathrm{Wnt} / \beta$-catenin/TGF- $\beta 1$ pathways are fundamental for LPS-induced MC proliferation; however, whether $\mathrm{Wnt} / \beta$-catenin or TGF- $\beta 1$ is upstream of this process requires further study.

The effectiveness of YQ for treating chronic nephritis has been indicated by previous studies in animal models and patients (19-21). The pharmacological mechanisms underlying the effects of this mixture have yet to be elucidated. There are 12 components of YQ, and many of these have previously been shown to exert regulatory effects on the Wnt pathway. Radix Astragali Mongolici (Huang Qi) is the main component of YQ, and Astragaloside IV (AS-IV) is the major active ingredient. In the unilateral ureteral occlusion (UUO) model of renal interstitial fibrosis, AS-IV was able to attenuate renal fibrosis and restore renal function by inhibiting TGF- $\beta 1$, connective tissue growth factor and $\alpha$-smooth muscle actin (SMA) expression, Smad2/3 phosphorylation, and collagen matrix expression, and upregulating Smad7. Similar results have been detected in TGF- $\beta 1$-stimulated rat renal NRK-49F fibroblasts. Knockdown of Smad7 significantly abrogated these effects, indicating that the renal protective effects of AS-IV occur predominantly via Smad7 and therefore the TGF- $\beta 1 /$ Smads pathway (32). Previous studies have demon- strated that there are synergistic effects of AS-IV and ferulic acid on TGF- $\beta 1, \alpha-S M A$, and p-JNK expression in the same rat and cell models of renal fibrosis (33). Astragaloside has also been shown to exert inhibitory effects on TGF- $\beta 1$, Wnt4, Wnt5a, Frizzled-2, -3, -6 and $\beta$-catenin expression in a cholestatic liver fibrosis rat model (34). Flos Lonicerae (Jin Yin Hua) together with Fructus Forsythiae Suspensae (Lian Qiao) have anti-inflammatory effects in rat models of chronic obstructive pulmonary disease, via inhibition of tumor necrosis factor- $\alpha$, TGF- $\beta 1$ and interleukin- $1 \beta$ expression, and there were synergistic effects of those two compounds with Radix Platycodon (35). In the UUO rat model, leonurine, the active component of Herba Leonuri (Yi Mu Cao) ameliorated renal tubulointerstitial fibrosis and inflammation via the TGF- $\beta / \mathrm{Smad} 3$ and nuclear factor- $\kappa \mathrm{B}$ pathway, indicating the potential renoprotective effect of leonurine (36). The regulatory effects of YQ in LPS-stimulated MCs via inhibition of the Wnt signaling pathway and TGF- $\beta 1$ expression may be due to the aforementioned mechanisms of the active components in YQ.

In conclusion, the results of the present study demonstrated that LPS is able to promote the proliferation of MCs and induce the increased expression of Wnt $4, \beta$-catenin and TGF- $\beta 1$. In addition, a positive correlation was detected between Wnt and TGF- $\beta 1$. Furthermore, YQ-S and For-S treatments were shown to reduce the mRNA and protein expression levels of Wnt $4, \beta$-catenin and TGF- $\beta 1$. Future studies are required in order to investigate the mechanisms underlying the effects of YQ-S and its component herbs on the Wnt and TGF- $\beta 1$ signaling pathways.

\section{Acknowledgements}

The present study was supported by the National Nature Science Foundation of China (grant nos. 81102588 and 81473614).

\section{References}

1. Martín-Cleary C and Ortiz A: CKD hotspots around the world: Where, why and what the lessons are. A CKJ review series. Clin Kidney J 7: 519-523, 2014.

2. Liyanage T, Ninomiya T, Jha V, Neal B, Patrice HM, Okpechi I, Zhao MH, Lv J, Garg AX, Knight J, et al: Worldwide access to treatment for end-stage kidney disease: A systematic review. Lancet 385: 1975-1982, 2015.

3. Duffield JS: Cellular and molecular mechanisms in kidney fibrosis. J Clin Invest 124: 2299-22306, 2014

4. Aihara K, Ikeda Y, Yagi S, Akaike M and Matsumoto T: Transforming growth factor- $\beta 1$ as a common target molecule for development of cardiovascular diseases, renal insufficiency and metabolic syndrome. Cardiol Res Pract 2011: $175381,2010$.

5. Herrera GA, Turbat-Herrera EA and Teng J: Mesangial homeostasis and pathobiology: Their role in health and disease. Contrib Nephrol 169: 6-22, 2011.

6. Kawakami T, Ren S and Duffield JS: Wnt signalling in kidney diseases: Dual roles in renal injury and repair. J Pathol 229: 221-231, 2013.

7. Barker N: The canonical Wnt/beta-catenin signaling pathway. Methods Mol Biol 468: 5-15, 2008.

8. Kikuchi A, Yamamoto H, Sato A and Matsumoto S: New insights into the mechanism of Wnt signaling pathway activation. Int Rev Cell Mol Biol 291: 21-71, 2011.

9. Macdonald BT, Semenov MV and He X: Snapshot: Wnt/beta-catenin signaling. Cell 131: 1204, 2007. 
10. He W, Dai C, Li Y, Zeng G, Monga SP and Liu Y: Wnt/beta-catenin signaling promotes renal interstitial fibrosis. J Am Soc Nephrol 20: 765-776, 2009.

11. He W, Tan RJ, Li Y, Wang D, Nie J, Hou FF and Liu Y: Matrix metalloproteinase-7 as a surrogate marker predicts renal Wnt/ $\beta$-catenin activity in CKD. J Am Soc Nephrol 23: 294-304, 2012.

12. Li Z, Xu J, Xu P, Liu S and Yang Z: Wnt/ $\beta$-catenin signalling pathway mediates high glucose induced cell injury through activation of TRPC6 in podocytes. Cell Prolif 46: 76-85, 2013

13. Dai C, Stolz DB, Kiss LP, Monga SP, Holzman LB and Liu Y: Wnt/beta-catenin signaling promotes podocyte dysfunction and albuminuria. J Am Soc Nephrol 20: 1997-2008, 2009.

14. Heikkilä E, Juhila J, Lassila M, Messing M, Perälä N, Lehtonen E, Lehtonen S, Sjef Verbeek J and Holthofer H: beta-Catenin mediates adriamycin-induced albuminuria and podocyte injury in adult mouse kidneys. Nephrol Dial Transplant 25 2437-2446, 2010.

15. Lin CL, Wang JY, Huang YT, Kuo YH, Surendran K and Wang FS: Wnt/beta-catenin signaling modulates survival of high glucose-stressed mesangial cells. J Am Soc Nephrol 17: 2812-2820, 2006

16. Lin CL, Cheng H, Tung CW, Huang WJ, Chang PJ, Yang JT and Wang JY: Simvastatin reverses high glucose-induced apoptosis of mesangial cells via modulation of Wnt signaling pathway. Am J Nephrol 28: 290-297, 2008.

17. Akhmetshina A, Palumbo K, Dees C, Bergmann C, Venalis P, Zerr P, Horn A, Kireva T, Beyer C, Zwerina J, et al: Activation of canonical Wnt signalling is required for TGF- $\beta$-mediated fibrosis. Nat Commun 3: 735, 2012.

18. Ho C, Lee PH, Hsu YC, Wang FS, Huang YT and Lin CL: Sustained Wnt $/ \beta$-catenin signaling rescues high glucose induction of transforming growth factor- $\beta 1$-mediated renal fibrosis. Am J Med Sci 344: 374-382, 2012

19. Zhan YL and Dai XW: Treatment of 30 cases with chronic nephritis with Yiqihuoxuejiedu formula. Zhong Yi Yao Tong Bao 44: 922 924, 2003 (In Chinese)

20. Zhan YL, Dai XW, Li XY, Li S and Rao XR: Renal protective effect of Yiqiqingre extract on adriamycin induced nephropathy. Chin West Med 4: 135 138, 2003 (In Chinese).

21. Zhan Y, Yang L, Wen Y, Liu H, Zhang H, Zhu B, Han W, Gu Y, Sun $X$, Dong $X$, et al: Yi qi qing re gao attenuates podocyte injury and inhibits vascular endothelial growth factor overexpression in puromycin aminonucleoside rat model. Evid Based Complement Alternat Med 2014: 375986, 2014.

22. Zu N, Li P, Li N, Choy P and Gong Y: Mechanism of saikosaponin-d in the regulation of rat mesangial cell proliferation and synthesis of extracellular matrix proteins. Biochem Cell Biol 85: 169-174, 2007.

23. Migliorini A, Ebid R, Scherbaum CR and Anders HJ: The danger control concept in kidney disease: Mesangial cells. J Nephrol 26: 437-449, 2013.
24. Zhou D, Li Y, Lin L, Zhou L, Igarashi P and Liu Y: Tubule-specific ablation of endogenous $\beta$-catenin aggravates acute kidney injury in mice. Kidney Int 82: 537-547, 2012.

25. Lin CL, Wang JY, Ko JY, Surendran K, Huang YT, Kuo YH and Wang FS: Superoxide destabilization of beta-catenin augments apoptosis of high-glucose-stressed mesangial cells. Endocrinology 149: 2934-2942, 2008.

26. Lin CL, Wang JY, Ko JY, Huang YT, Kuo YH and Wang FS: Dickkopf-1 promotes hyperglycemia-induced accumulation of mesangial matrix and renal dysfunction. J Am Soc Nephrol 21: 124-135, 2010.

27. Villa L, Boor P, Konieczny A, Kunter U, van Roeyen CR, Denecke B, Gan L, Kupper MB, Hoffmann K, Eitner F, et al: Effects and mechanisms of angiotensin II receptor blockade with telmisartan in a normotensive model of mesangioproliferative nephritis. Nephrol Dial Transplant 26: 3131-3143, 2011.

28. Tveita AA and Rekvig OP: Alterations in Wnt pathway activity in mouse serum and kidneys during lupus development. Arthritis Rheum 63: 513-522, 2011.

29. López-Hernández FJ and López-Novoa JM: Role of TGF- $\beta$ in chronic kidney disease: An integration of tubular, glomerular and vascular effects. Cell Tissue Res 347: 141-154, 2012.

30. Lee HS and Song CY: Differential role of mesangial cells and podocytes in TGF-beta-induced mesangial matrix synthesis in chronic glomerular disease. Histol Histopathol 24: 901-908, 2009.

31. Zhang P, Cai Y, Soofi A and Dressler GR: Activation of Wnt11 by transforming growth factor- $\beta$ drives mesenchymal gene expression through non-canonical Wnt protein signaling in renal epithelial cells. J Biol Chem 287: 21290-21302, 2012.

32. Wang L, Chi YF, Yuan ZT, Zhou WC, Yin PH, Zhang XM, Peng W and Cai H: Astragaloside IV inhibits renal tubulointerstitial fibrosis by blocking TGF- $\beta /$ Smad signaling pathway in vivo and in vitro. Exp Biol Med (Maywood) 239: 1310-1324, 2014.

33. Meng LQ, Tang JW, Wang Y, Zhao JR, Shang MY, Zhang M, Liu SY, Qu L, Cai SQ and Li XM. Astragaloside IV synergizes with ferulic acid to inhibit renal tubulointerstitial fibrosis in rats with obstructive nephropathy. Br J Pharmacol 162: 1805-1818, 2011.

34. Yongping M, Zhang X, Xuewei L, Fan W, Chen J, Zhang H, Chen G, Liu C and Liu P: Astragaloside prevents BDL-induced liver fibrosis through inhibition of notch signaling activation. J Ethnopharmacol 169: 200-209, 2015.

35. Li YH, Zheng FJ, Huang Y, Zhong XG and Guo MZ: Synergistic anti-inflammatory effect of Radix Platycodon in combination with herbs for cleaning-heat and detoxification and its mechanism. Chin J Integr Med 19: 29-35, 2013.

36. Cheng H, Bo Y, Shen W, Tan J, Jia Z, Xu C and Li F: Leonurine ameliorates kidney fibrosis via suppressing TGF- $\beta$ and NF- $\mathrm{B}$ signaling pathway in UUO mice. Int Imunopharmacol 25: 406-415, 2015. 